\title{
Removal of Humic Substances from Water by Means of Fibrous lon Exchanger
}

\author{
Henryk Wasąg' \\ 1 Faculty of Environmental Engineering, Lublin University of Technology, Nadbystrzycka 40B, 20-618 Lublin, \\ Poland \\ e-mail: h.wasag@pollub.pl
}

\begin{abstract}
Natural organic substances are found in all natural waters, and especially high concentrations occur in the surface waters. Humic substances, which often constitute the majority of natural pollutants, can be the source of undesirable odor and increased color as well as may accumulate certain toxic substances through sorption or formation of complexes. Another threat connected with the presence of humic substances in water is the possibility of the trihalomethanes (THM) formation during disinfection with chlorine. Additionally, it disturbs most processes employed for treatment of water. Hence, the great interest in the development of the pretreatment methods enabling to reduce the content of humic substances prior to the further water treatment processes. According to many researchers, ion exchange is an effective method for removing humic substances from drinking water supplies. However, the obtained effects are strictly dependent on the properties of the employed ion exchangers. The paper presented the studies on the removal of humic substances from water using fibrous ion exchangers. Owing to their structure, fibrous ion exchangers are characterized by very good kinetics of the sorption process, which enables the application of thin layers with simultaneous high flow velocity. Fiban A-1 - strong base anion fibrous exchanger, synthesized in the Institute of Physical Organic Chemistry of the National Academy of Sciences of the Republic of Belarus was employed in the presented laboratory studies on the treatment of surface water containing substantial amounts of humic substances (over $10 \mathrm{~g} / \mathrm{m}^{3}$ ). The applied anion exchange resin allows for efficient elimination of humic substances from the treated water, whereas the obtained sorption value, reaching approximately $20 \mathrm{mg} / \mathrm{g}$ of ion exchanger allowed treating about 255-270 bed volumes of water under the conditions of the experiment. The exhausted Fiban A-1 ion exchanger can be successfully regenerated using $2 \% \mathrm{NaCl}+2 \% \mathrm{NaOH}$ solution, as five consecutive operational cycles showed no reasonable decrease in the amount of purified water.
\end{abstract}

Keywords: ion exchange, drinking water, humic substances, fibrous ion exchangers

\section{INTRODUCTION}

The increasingly stringent regulations related to the water for consumption require the application of more efficient treatment technologies. Simultaneously, the observed deficit of water resources, especially of high quality, necessitates the usage of water contaminated by multiple substances, both of the anthropogenic and natural origin. The natural pollutants occurring in surface waters which mainly include humic substances, as well as the metabolic products of microorganisms and the compounds from the decomposition of dead microorganisms, are grouped under a common term natural organic matter (NOM) [Sharma
\& Bhattacharya, 2017]. Humic substances (HS) are found in almost all natural waters, especially in some surface waters. HS directly affect the organic pollution level and color of water. They constitute approximately $60-80 \%$ of total mass of organic substance in waters and bottom sediments [Bhatnagara \& Sillanpää, 2017]. Natural organic matter does not pose a direct threat to the health of consumers; however, they may be a source of undesirable taste and odor. In the past, if they were removed from water, it was only due to the aesthetic reasons. However, the constantly conducted studies the quality of water showed that humic substances can accumulate some toxic pollutants by forming complexes with heavy 
metals, phosphorus and ammonia compounds, or through sorption of organic compounds, e.g. polycyclic aromatic hydrocarbons (PAHs), pesticides and phthalates [Molczan \& Szlachta, 2011]. However, the greatest threat connected with the presence of humic substances in water is the fact that they may constitute precursors of chlorinated organic compounds, which are known carcinogens [Tan et al., 2005].

Therefore, efficient removal of humic substances contained in natural waters constitutes one of the current challenges for the contemporary water treatment technologies. Among the numerous physical, chemical and biological processes employed for the removal of natural organic substances, the methods based on coagulation, sometimes supplemented with sorption using activated carbon, are the most common in practice [Yue Zhang et al., 2015]. The constantly developed and improved non-conventional processes become increasingly common. These mainly include membrane processes, such as: ultrafiltration, nanofiltration, reverse osmosis, as well as combined membrane techniques and other physicochemical processes [Cornelissen et al., 2009]. However, in the opinion of numerous scientists, the presence of humic substances in the treated water significantly hinders the application of the commonly employed conventional methods and significantly lowers their efficiency. This is because NOM strongly affects water treatment processes, e.g. by reducing the efficiency of activated carbon or causing membrane fouling problems [KabschKorbutowicz \& Urbanowska, 2012]. Therefore, a constantly growing interest in the development of inexpensive and efficient pretreatment methods, enabling to reduce the content of humic substances prior to the further water treatment processes. The attention of numerous scientists is drawn to the sorption methods, commonly considered as most universal. As revealed from the literature reviewed, modified adsorbents, composite materials and a few nanomaterials have shown very promising results in the removal of humic substances from water [Fettig, 1999]. Out of the wide variety of the tested sorbents, attention is often drawn on ion exchangers. According to many researchers, ion exchange is an effective method for removing humic substances from drinking water supplies [Audemaert et al., 2016]. The humic substances contained in surface water can be removed by ion exchange, because the main part of humic substances is negatively charged (Bolto et al., 2003). The method is relatively cost effective, easy to operate and a compact installation which can be used due to the short contact times [Bolto et al., 2004]. The efficiency of humic substances removal by ion exchange depends on many factors i.a. concentration and composition of humic substances, type of resin, empty bed contact time and configuration of the ion exchange installation. The bed size of the resin, water retention, capacity and functional groups of the resin will also influence the removal efficiency [[Grefte et al., 2013]. Resins of high water content are confirmed as the better performers, being very efficient at removal of any charged material, especially that of smaller molecular size. A significant increase in humic substances removal for quaternary ammonium resins was observed for the more open structures allowing easier entry of the larger species [Levchuk et al., 2018]. These observations indicate that the application of fibrous ion exchangers with easily available function groups distributed on the surface of very thin fibers may significantly facilitate the removal of humic substances from the treated water. The objective of this research is to improve the drinking water quality by incorporating the ion exchange process conducted by Fiban A-1 fibrous ion exchanger for the removal of humic substances.

\section{MATERIALS AND METHODS}

Natural surface water containing humic substances, collected from the southern part of the Zemborzyce Lake (Lublin) characterized by low water turnover rate and located adjacent to a peat bog, was used in the conducted studies. The removal of humic substances from water was performed using Fiban A-1 fibrous ion exchanger, synthesized in Institute of Physical Organic Chemistry of the National Academy of Sciences of the Republic of Belarus. Strong base fibre Fiban A-1 is a product of chloromethylation and subsequent amination of the styrene-divinylbenzene grafted copolymer with trimethylamine. The basic properties of the investigated ion exchanger were presented in Table 1.

Very high speed of sorption processes conducted with fibrous ion exchangers makes it possible to use thin layers of material $(10-20 \mathrm{~mm})$, the resistance of which is easily controlled by their packing density $\left(0.1-0.25 \mathrm{~g} / \mathrm{cm}^{3}\right)$. 
Table 1. Properties of Fiban A-1 fibrous anion exchanger (by https://ifoch.by)

\begin{tabular}{|l|l|}
\hline Polymer base & Polypropylene fiber with graft copolymer of styrene and divinylbenzene. \\
\hline Physical form & $\begin{array}{l}\text { Staple fiber. Non-woven needle-punched fabric with a surface density } \\
\text { of } 250-1000 \mathrm{~g} / \mathrm{m}^{2} \text {. Blade width up to } 160 \mathrm{~cm} \text {, thickness } 3-12 \mathrm{~mm} .\end{array}$ \\
\hline $\begin{array}{l}\text { Optimal capacity } \\
\mathrm{mEq} / \mathrm{g}\end{array}$ & Not less than 2.7 . Materials with a larger or smaller exchange capacity can be made. \\
\hline $\begin{array}{l}\text { Optimal swelling, } \\
\mathrm{g} \mathrm{H}_{2} \mathrm{O} / \mathrm{g} \text { fiber }\end{array}$ & 0.8 \\
\hline $\mathrm{pH}$ working range & $0-14$ \\
\hline Working temperature range & $\begin{array}{l}\text { up to } 100^{\circ} \mathrm{C}(\mathrm{Cl}-\text { form), } \\
\text { up to } 50^{\circ} \mathrm{C}(\mathrm{OH} \text {-form). }\end{array}$ \\
\hline $\begin{array}{l}\text { Resistance to aggressive } \\
\text { environments }\end{array}$ & $\begin{array}{l}\text { Stable at room temperature in } 0.5 \mathrm{~N} \text { solutions of acids, alkalis, NaCl. Stable in } \\
\text { oxidizing environments. }\end{array}$ \\
\hline
\end{tabular}

The chemical reagents used in the studies were manufactured and distributed by Merck, Germany. All the solutions were prepared with bidistilled water. The concentrations of humic substances were determined by the spectrophotometric method with the use of Hitachi UV/VIS spectrophotometer U-1500 [Hanschmann, 1991].

The sorption of humic substances from natural surface water was performed on a strong base Fiban A-1 fibrous anion exchanger. Two ion exchange columns with the diameter of $2 \mathrm{~cm}$ packed with $4 \mathrm{~g}$ of air dry ion exchanger were prepared for this purpose. At the bed height of $10 \mathrm{~cm}$, the ion exchanger packing density was approximately $0.13 \mathrm{~g} / \mathrm{cm}^{3}$. The dry ion exchanger in columns was swelled for $24 \mathrm{~h}$ in distilled water. Afterwards, the ion exchangers were regenerated using $100 \mathrm{~cm}^{3} 5 \% \mathrm{NaCl}$ solution and then rinsed with distilled water. The ion exchange beds prepared in this way were used in further research.

\section{Selection of the regeneration method}

In order to select an efficient method for the regeneration of the ion exchange resin from the adsorbed humic substances, both beds were subjected to exhaustion by supplying the investigated water with the initial content of humic substances of $11.5-12.0 \mathrm{mg} / \mathrm{dm}^{3}$ at the rate of $10 \mathrm{~m} / \mathrm{h}$ until $50 \%$ of the initial concentration was achieved in the leachate. One bed was regenerated by means of $5 \% \mathrm{NaCl}$ solution, whereas the other with $2 \% \mathrm{NaCl}+2 \% \mathrm{NaOH}$ solution (both regenerants were used in similar molar concentrations). Following the application of $200 \mathrm{~cm}^{3}$ regenerating solution to each column, the ion exchangers were rinsed with distilled water. Following the regeneration and rinsing processes, the effluent fractions, each with the volume of
$20 \mathrm{~cm}^{3}$, were collected and the content of humic substances was determined.

\section{Removal of humic substances}

After the selection of regeneration method, another 4 full cycles of the ion exchanger operation were conducted, involving exhaustion, regeneration and rinsing of the bed. During exhaustion, conducted at the rate of $10 \mathrm{~m} / \mathrm{h}$, the effluent fractions with the volume of $500 \mathrm{~cm}^{3}$ each were collected and analyzed in terms of the content of humic substances. The process was continued until the breakthrough point, set at $50 \%$ of initial concentration, was achieved. Then, the ion exchanger was regenerated for at least 30 minutes using $100 \mathrm{~cm}^{3}$ of $2 \% \mathrm{NaCl}+2 \% \mathrm{NaOH}$ solution, followed by rinsing with distilled water.

\section{RESULTS AND DISCUSSION}

The usefulness and possibility of practical application of each sorbent in the pollutant removal process correspond not only to its sorption properties, but also to efficient regeneration enabling its reuse in cyclic technological processes. Restoration of the initial ion exchange capacity, simultaneously minimizing the volume of generated liquid wastes, constitute the factors governing the attractiveness of the method. The course of the regeneration process employed in the studies on a strongly alkaline Fiban A-1 fibrous ion exchanger exhausted with humic substances was illustrated in Figure 1.

Application of the $\mathrm{NaCl}$ solution for ion exchange regeneration is common in various ion exchange processes, enabling efficient desorpion of humic compounds, which can be inferred from 


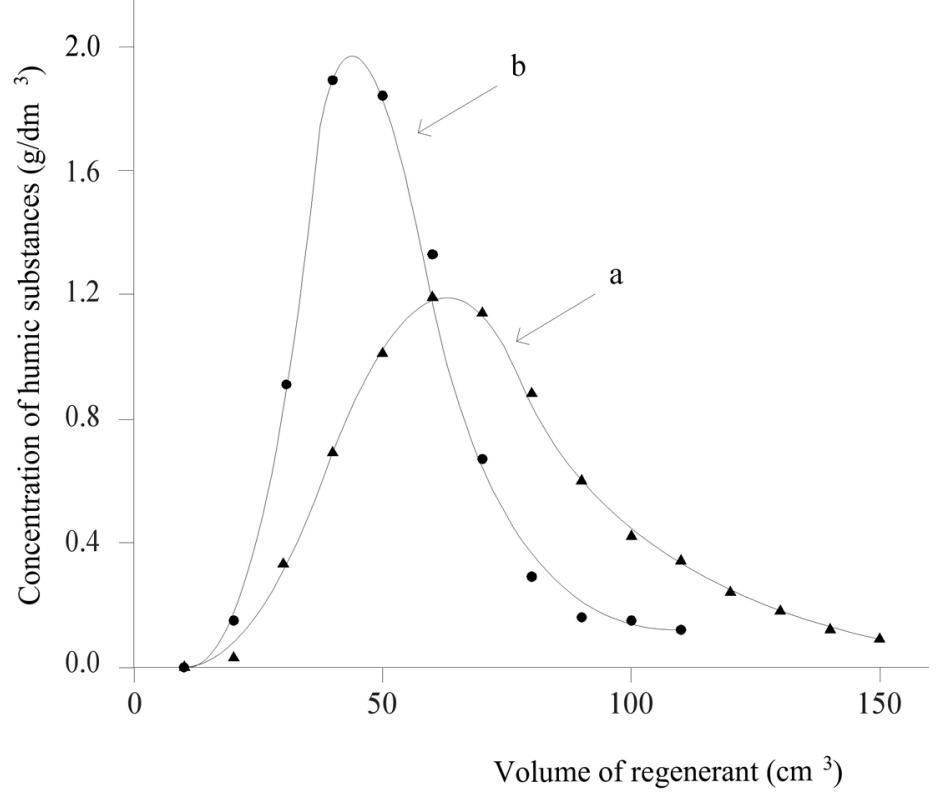

Figure 1. Regeneration of the Fiban A-1 fiber using different solutions: $a-5 \% \mathrm{NaCl}, \mathrm{b}-2 \% \mathrm{NaCl}+2 \% \mathrm{NaOH}$

the exhaustion curve a (Fig. 1). In the initial regeneration period, the concentration of humic substances in the regeneration effluent subsequently increases. Its maximum is observed at about 2 bed volumes of the leachate and approximates $1.2 \mathrm{~g} / \mathrm{dm}^{3}$. As the regeneration progresses, a gradual but slow decrease in the concentration of humic substances in the regeneration effluent is observed. At approximately $4-5$ bed volumes of the used $5 \% \mathrm{NaCl}$ solution, the regeneration process can be considered as completed. The efficiency of such regeneration, evaluated by means of the amount of desorbed humic substances from the ion exchange bed, reaches about $87-92 \%$ depending on then it finishes. However, comparing the curves presented in Figure 1, it can be observed that the application of $2 \% \mathrm{NaCl}+2 \% \mathrm{NaOH}$ solution yields better results while regenerating the Fiban A-1 fibrous ion exchanger exhausted with humic compounds. In this case, the observed rate of humic substances concentration increase in the regeneration effluent is higher, and the maximum concentration is achieved already at about $1.3-1.5$ bed volumes. In addition, comparing to the regeneration conducted with $5 \% \mathrm{NaCl}$ solution, the maximum concentration is much higher and reaches almost $2 \mathrm{~g} / \mathrm{dm}^{3}$. Following the application of 2 bed volumes of the regeneration solution, the concentration of humic substances in the leachate drops to about $1 / 3$ of its maximum value, and the desorption is practically finished after applying about 3 bed volumes of the regenerating solution. Moreover, the regeneration of the anion exchanger with a $2 \% \mathrm{NaOH}+2 \% \mathrm{NaCl}$ solution enables achieving about $94 \%$ desorption of humic substances. Therefore, taking into account the regeneration efficiency, as well as - primarily - the volumes of the generated and troublesome post-regeneration solutions, the application of $2 \% \mathrm{NaCl}+2 \% \mathrm{NaOH}$ solution is preferable. Thus, this regenerant was used in the further studies in the course of cyclic ion exchange processes involving the removal of humic substances from water (ion exchange exhaustion), regeneration of the ion exchange bed and its post-regeneration rinsing. The results of the conducted studies involving 5 consecutive operation cycles of an ion exchange with a bed of strong base Fiban A-1 fiber were presented in Table 2, while the graphical comparison of the removal of humic substances from water during the I and $\mathrm{V}$ operation cycle were shown in Figure 2.

While analyzing the data presented in Table 2, it can be observed that the fibrous ion exchanger Fiban A-1 enables efficient removal of humic substances from water. However, even at the very beginning the treated water is not entirely free of pollution. The situation is similar in the following cycles of ion exchanger operation and it can be stated that the process conducted in this way enables to remove up to $90 \%$ of the humic substances from water. This corresponds to the observations of other scientists evaluating the usefulness of the ion exchange processes for the removal of these pollutants. This is usually attributed to the fact that about $10 \%$ of humic 


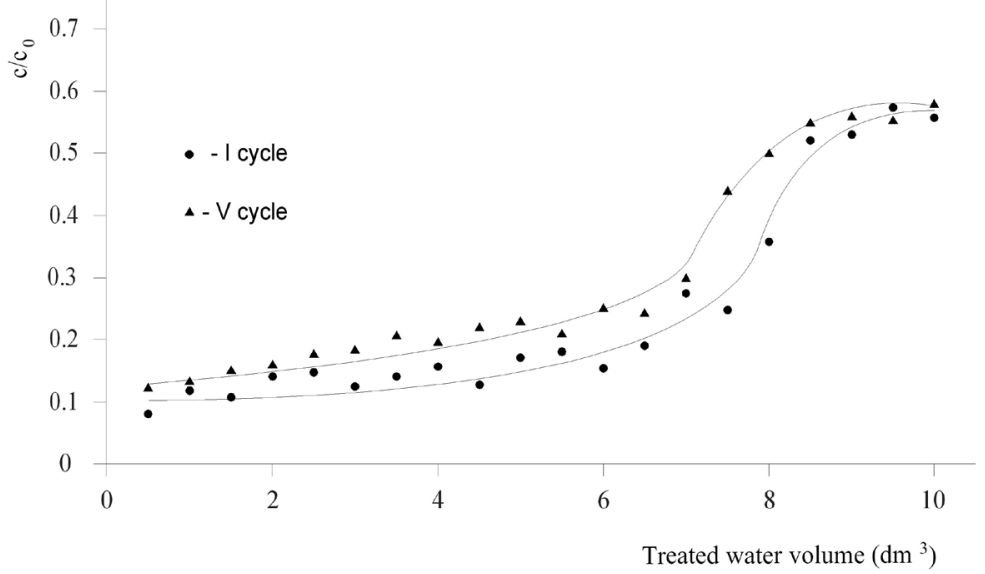

Figure 2. Concentration of humic substances in the treated water during consecutive operations cycles of Fiban A-1 fiber

substances contained in water does not dissociate and thus does not exhibit the ionic nature [Drikas et al., 2011]. The exhaustion process itself does not show a typical course for the majority of the ion exchange processes. While removing humic substances from water by means of Fiban A-1 fibre, a slow continuous increase in their content is observed in effluent, as indicated by the data in Table 2. As the process progresses, the rate of this increase grows, which is characteristic for the typical exhaustion curves. Taking this into account, the process itself and the assessment of its efficiency were conducted in relation to the breakthrough point determined at $50 \%$ of the initial concentration. Even under the technological conditions, this is an acceptable value, because

Table 2. Changes in the concentration of humic substances in the water treated by means of the Fiban A-1 ion exchanger and selected data characteristic for the subsequent process cycles

\begin{tabular}{|c|c|c|c|c|c|}
\hline \multirow{2}{*}{ Treated water volume $\left(\mathrm{dm}^{3}\right)$} & \multicolumn{5}{|c|}{ Concentration of humic substances c $\left(\mathrm{mg} / \mathrm{dm}^{3}\right)$} \\
\cline { 2 - 6 } & I cycle & II cycle & III cycle & IV cycle & V cycle \\
\hline 0.5 & 0.93 & 1.55 & 1.29 & 1.58 & 1.38 \\
\hline 1.0 & 1.40 & 1.32 & 1.64 & 1.21 & 1.49 \\
\hline 1.5 & 1.28 & 1.67 & 1.41 & 1.33 & 1.72 \\
\hline 2.0 & 1.63 & 1.79 & 1.76 & 1.46 & 1.84 \\
\hline 2.5 & 1.69 & 2.03 & 2.11 & 2.06 & 2.07 \\
\hline 3.0 & 1.46 & 1.67 & 1.64 & 1.94 & 2.12 \\
\hline 3.5 & 1.65 & 1.91 & 2.00 & 2.43 & 2.41 \\
\hline 4.0 & 1.86 & 2.15 & 2.00 & 2.30 & 2.24 \\
\hline 4.5 & 1.51 & 2.03 & 2.23 & 2.79 & 2.53 \\
\hline 5.0 & 1.98 & 2.27 & 2.11 & 2.91 & 2.64 \\
\hline 5.5 & 2.10 & 2.39 & 2.58 & 2.30 & 2.41 \\
\hline 6.0 & 1.80 & 2.75 & 2.23 & 2.91 & 2.87 \\
\hline 6.5 & 2.21 & 2.75 & 2.58 & 3.03 & 2.76 \\
\hline 7.0 & 3.20 & 3.35 & 3.05 & 3.76 & 3.44 \\
\hline 7.5 & 2.85 & 4.19 & 3.87 & 5.22 & 5.05 \\
\hline 8.0 & 4.19 & 4.90 & 4.46 & 5.58 & 5.74 \\
\hline 8.5 & 6.05 & 6.10 & 5.52 & 6.19 & 6.31 \\
\hline 9.0 & 6.17 & 6.10 & 6.22 & 6.91 & 6.43 \\
\hline 9.5 & 6.69 & 6.70 & 6.81 & 6.55 & 6.31 \\
\hline 10.0 & 6.40 & 7.30 & 6.57 & 7.28 & 6.66 \\
\hline Bnitial concentration c $\left(\right.$ mg/dm $^{3}$ ) & 11.64 & 11.96 & 11.74 & 12.13 & 11.48 \\
\hline Amount of absorbed humic substances until & 270 & 270 & 270 & 255 & 270 \\
\hline breakthrough point (mg/g of ion exchanger) & 20.0 & 19.8 & 19.6 & 18.9 & 18.3 \\
\hline & & & & \\
\hline
\end{tabular}


after averaging the stream of the treated water, it corresponds to over $80 \%$ reduction in the content of these pollutants. Under the process conditions, the volume of treated water in a single operation cycle amounts to over 250 bed volumes, which in turn corresponds to the working sorption capacity comparable to $20 \mathrm{mg} / \mathrm{g}$ of ion exchange resin. A possible threat of reduced ion exchange efficiency which can be easily indicated in the treatment of water containing organic substances, is their partial deactivation caused by the irreversible sorption processes, partially dependent on the type and composition of the ion exchange resin [Bolto et al., 2003]. While analyzing the research results presented in Table 2, it can be seen that fibrous ion exchangers also exhibit this drawbacks. The analysis of the treated water volume for achieving the predetermined breakthrough point does not clearly indicate a drop in the sorption capacity of the ion exchange resin, because the obtained volumes of treated water following five consecutive operational cycles are comparable and amount to 255-270 bed volumes. However, the comparison of the amount of humic substances sorbed from water by $1 \mathrm{~g}$ of ion exchanger in consecutive operation cycles indicates a slowly progressing deactivation of the bed (Tab. 2). A more thorough assessment of this phenomenon is possible when comparing the exhaustion curves in two ion exchanger operation cycles which are furthest apart (see Fig. 2). The presented data pertaining to the concentrations of humic substances in successive fractions of treated water indicate that they are generally higher in the fifth cycle than those observed in the first one. The breakthrough point set at $50 \%$ of the initial concentration is achieved with less prominent changes in concentration, hence the comparable volumes of treated water in consecutive operation cycles, despite the drop in the amount of adsorbed humic substances by unit amount of ion exchanger, which was reported earlier.

\section{CONCLUSIONS}

The conducted preliminary studies on the removal of humic substances from surface water confirmed the possibility of using strong base fibrous ion exchanger, i.e. Fiban A1, for this purpose. The relevant observations include the high efficiency of the employed ion exchanger in removing humic substances from water, its high sorption capacity and possibility of successful regeneration. Regeneration of the exhausted ion exchanger using $2 \% \mathrm{NaCl}+2 \% \mathrm{NaOH}$ solution enables to remove over $90 \%$ of the adsorbed humic substances, already by applying 3 bed volumes of the regeneration solution. The high regeneration efficiency enables to reuse the ion exchanger multiple times, and the obtained results indicate only a negligible drop in the sorption capacity of Fiban A-1, which has no practical effect on the volume of treated water in consecutive operation cycles. Under the experimental conditions, the sorption of humic substances approximating $20 \mathrm{mg} / \mathrm{g}$ of ion exchanger enabled treating $255-270$ bed volumes of water, simultaneously at high flow rate and low bed height (10 $\mathrm{m} / \mathrm{h}$ and $10 \mathrm{~cm}$, respectively).

\section{REFERENCES}

1. Audemaert W., Benden L., Hulle S. 2016. Removal of natural organic matter (NOM) by ion exchange from surface water for drinking water production: a pilot-scale study. Desalination and Water Treatment, 57(30), 13897-13908.

2. Bhatnagara A., Sillanpää M. 2017. Removal of natural organic matter (NOM) and its constituents from water by adsorption - A review. Chemosphere, 166, 497-510.

3. Bolto B., Dixon D., Eldridge R., King S., Linge K.L. 2003. Removal of natural organic matter by ion exchange. Water Research, 36(20), 5057-65.

4. Bolto B., Dixon D., Eldridge R. 2004. Ion exchange for the removal of natural organic matter. Reactive and Functional Polymers, 60(1),171-182.

5. Cornelissen E. R., Beerendonk E. F., Nederlof M. N., van der Hoek J. P., Wessels L. P. 2009. Fluidized ion exchange (FIX) to control NOM fouling in ultrafiltration. Desalination, 236, 334-341.

6. Drikas M., Dixon M., Morran J. 2011. Long term case study of MIEX pre-treatment in drinking water; understanding NOM removal. Water Research, 45(4), 1539-1548.

7. Fettig J. 1999. Removal of humic substances by adsorption/ion exchange. Water Science and Technology, 40(9), 173-182.

8. Grefte A., Dignum M., Cornelissen E. R., Rietveld L. C. 2013. Natural organic matter removal by ion exchange at different positions in the drinking water treatment lane. Drinking Water Engineering and Science, 6(1), 375-401.

9. Hanschmann G. 1991. A simple extraction-spectrophotometric method for the estimation of dissolved 
humic substances in water. Part 1: Procedures. Clean - Soil Air Water, 19(3), 265-266.

10. Kabsch-Korbutowicz M., Urbanowska A. 2012. Advantages of using the ion-exchange process in NOM removal prior to water ultrafiltration. Proc. Advances in Civil, Environmental and Materials Research (ACEM' 12), 388-397.

11. Levchuk I., Rueda Márquez J. J., Sillanpää M. 2018. Removal of natural organic matter (NOM) from water by ion exchange - A review. Chemosphere, 192, 90-104.

12. Molczan M., Szlachta M. 2011. Anion exchange pretreatment for the removal of natural organic matter from humic rich water. Water Science and Technology: Water Supply, 11(6), 699-710.

13. Sharma S., Bhattacharya A. 2017. Drinking water contamination and treatment techniques. Applied Water Science, 7(3), 1043-1067.

14. Tan Y., Kilduff J. E., Kitis M., Karanfil T. 2005. Dissolved organic matter removal and disinfection byproduct formation control using ion exchange. Desalination, 176, 189-200.

15. Yue Zhang, Xinhua Zhao, Xinbo Zhang, Sen Peng. 2015. A review of different drinking water treatments for natural organic matter removal. Water Supply, 15(3), 442-455. 